\title{
Milk fat triacylglycerols and their relations with milk fatty acid composition, DGAT1 K232A polymorphism, and milk production traits
}

\author{
D. A. Tzompa-Sosa, ${ }^{*}$ H. J. F. van Valenberg, ${ }^{* 1}$ G. A. van Aken, $† \ddagger$ and H. Bovenhuis§ \\ *Dairy Science and Technology Group, Food Quality and Design, Wageningen University, Wageningen, 6708WG, the Netherlands \\ †NIZO Food Research, PO Box 2, 6710 BA, Ede, the Netherlands \\ łlnsight FOOD inside, $6711 \mathrm{BE}$, Ede, the Netherlands \\ $\S$ Animal Breeding and Genomics Centre, Wageningen University, Wageningen, 6708WG, the Netherlands
}

\begin{abstract}
Milk fat (MF) triacylglycerols (TAG) determine the physical and functional properties of butter and products rich in MF. To predict these properties, it is necessary to understand the variability of fatty acids, TAG, their associations, and their effect on milk productive traits, days in milk (DIM), and genes related to fat synthesis. Therefore, the aim of this research was to study the variability of TAG using MF from individual cows and to investigate the effect of fatty acid composition, DGAT1 K232A polymorphism, DIM, and milk production traits (fat content and morning milk yield) on MF TAG profile in the Dutch Holstein-Friesian dairy cattle population. Large differences in MF TAG profiles were seen among cows. We showed that the variability of TAG is highest for low and high molecular weight TAG [TAG with carbon numbers (Cn) 26-30 and Cn52-54, respectively] and lowest for TAG with $\mathrm{Cn} 38$, which was the most abundant TAG. Saturation index (saturated fatty acid/unsaturated fatty acid) and the ratio C16:0/ C18:1 cis-9 showed significant effects on TAG Cn34, Cn36, Cn52, and Cn54: TAG Cn34 and Cn36 increased as the saturation index and ratio $\mathrm{C} 16: 0 / \mathrm{C} 18: 1$ cis-9 increased, whereas the opposite was seen for TAG Cn52 and Cn54. Moreover, the DGAT1 K232A polymorphism significantly affected TAG Cn38. We showed that the relative concentration of TAG with $\mathrm{Cn} 38$ was higher in cows with DGAT1 KK genotype. Production traits (fat content and morning milk yield) and DIM had no significant effect on TAG profile. This is a relevant observation because considerable increases of milk yield and fat content have been seen in the Netherlands over the last $60 \mathrm{yr}$. The large differences shown between individual cows in MF TAG profile imply differences in physical properties of MF.
\end{abstract}

Received November 3, 2015.

Accepted January 20, 2016.

${ }^{1}$ Corresponding author: hein.vanvalenberg@wur.nl
Key words: triacylglycerol, milk fat, DGAT1, milk productive trait, milk synthesis

\section{INTRODUCTION}

Milk fat (MF) triacylglycerols (TAG) determine the physical and functional properties of butter and products rich in MF (Parodi, 1979; Hawke and Taylor, 1995). However, predicting the functional properties of these products is difficult because these properties are influenced not only by fatty acid composition, but also by the positioning of fatty acids within the glycerol backbone and by the concentration of individual TAG species. Moreover, it is known that the concentration of fatty acids, the positioning of fatty acids within the TAG, and the concentration of TAG species change among seasons and feeding regimens (Gresti et al., 1993; Capuano et al., 2013; Tzompa-Sosa et al., 2014). These characteristics of TAG are largely regulated by the availability of fatty acids present in the system and by the enzymes involved in lipid synthesis, which respond to genetic factors (Bionaz and Loor, 2008; Smiddy et al., 2012; Tzompa-Sosa et al., 2014).

Milk fat TAG is synthesized via the glycerol3 -phosphate pathway. Its reactions are catalyzed by 4 enzymes, namely glycerol-phosphate acyltransferase, acylglycerol-phosphate acyltransferase, phosphatidic acid phosphohydrolase, and diacylglycerol acyltransferase (DGAT; Coleman and Lee, 2004). A change in the AA sequence of an enzyme could result in a change of its function such as the one reported for DGAT1 K232A polymorphism. The DGAT1 K allele has been associated with decreased milk yield $(\mathrm{kg})$ and increased in fat content (\%), higher concentration of saturated fat and C16:0, and a lower concentration of C14:0, unsaturated C18, and CLA (Schennink et al., 2007). Moreover, DGAT1 K232A polymorphism has been associated with a change in the positioning of the fatty acids within the TAG (Tzompa-Sosa et al., 2014).

Bovine MF is composed of TAG with a carbon number (Cn) between 22 and 54 (Gresti et al., 1993; 
Ruiz-Sala et al., 1996). Most studies agree that the concentrations of individual TAG vary among seasons and feeding regimens (DePeters et al., 2001; Capuano et al., 2013). For instance, MF of cows in pasture is rich in unsaturated $\mathrm{C} 18$ fatty acids; has a decreased relative concentration of TAG Cn34, Cn36, Cn42, Cn44, and $\mathrm{Cn} 46$; and has an increased relative concentration of TAG Cn24, Cn26, Cn40, Cn50, Cn52, and Cn54, as compared with cows in a winter diet with no fresh grass (Capuano et al., 2013). A similar effect has been reported for cows with dietary oil supplementation (DePeters et al., 2001). Overall, studies agree that diets rich in unsaturated $\mathrm{C} 18$ fatty acids, such as fresh grass or canola supplementation, increase the relative concentrations of TAG $\mathrm{Cn} 52$ and $\mathrm{Cn} 54$ and decrease the relative concentration of TAG Cn34, Cn42, and Cn44.

The effect of feeding on MF TAG profile in pooled samples (DePeters et al., 2001; Capuano et al., 2013) and the effect of DGAT1 K232A polymorphisms on the fatty acid profile have been previously studied (Schennink et al., 2007); however, no information about variability of MF TAG in a dairy cow population using individual samples or the effect of DGAT1 K232A polymorphism on TAG profile have been reported. Understanding the variability of MF TAG in a cow population and the role of fatty acid composition, DGAT1 K232A polymorphism, and milk productive traits on the variation of MF TAG profiles can help to find opportunities to modify physical properties of MF. The advantage of using MF from individual cows over bulk milk is that information on fatty acid composition, productive traits, and the genetic background of each individual cow is available and can be related to changes in TAG profile. The aim of this research was to study the variability of TAG on MF from individual cows, as well as to investigate the effect of fatty acid composition, DGAT1 K232A polymorphism, and milk production traits (fat content, morning milk yield) and DIM on MF TAG profile in the Dutch Holstein-Friesian dairy cattle population.

\section{MATERIALS AND METHODS}

\section{Sample Selection of Individual Milk Fats from a Population of Dutch Holstein-Friesian Cows}

The MF samples and fatty acid compositions used in this study were part of the Dutch Milk Genomics Initiative where morning milk samples were collected from 1918 first-lactation Holstein-Friesian cows on 398 commercial farms in the Netherlands (Schennink et al., 2007; Heck et al., 2012). The fatty acid composition of this population has been previously reported and

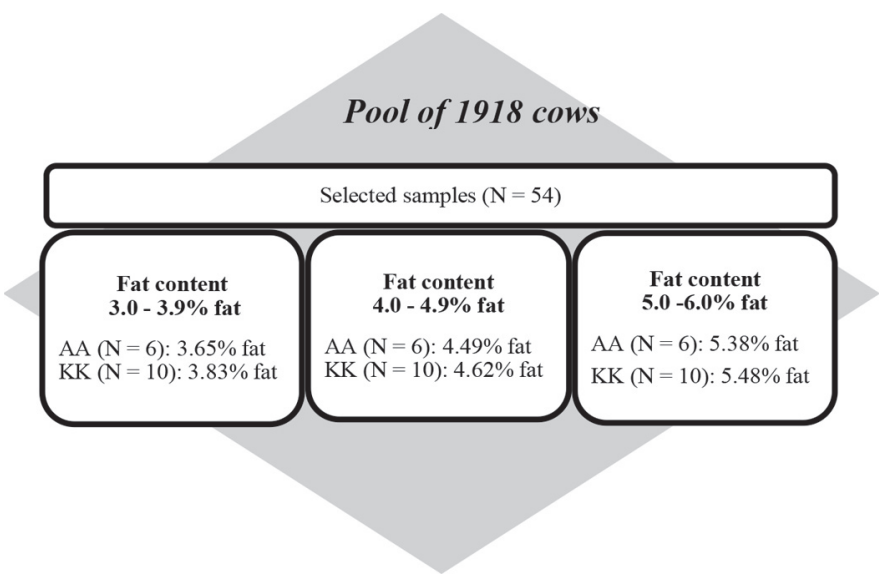

Figure 1. Sample selection of individual milk fats from a population of Dutch Holstein-Friesian cows.

discussed (Stoop et al., 2008; Heck et al., 2012). Milk samples were collected during the months February and March, which corresponds to the winter season in the Netherlands. The typical winter diet in the Netherlands consists mainly of concentrate, corn, and grass silage (Heck et al., 2009).

In the current study, we ensured a large variation in fat content, and consequently in fatty acid composition, by randomly selecting a similar number of MF samples from cows with a fat content from 3.0 to $3.9 \%$, from 4.0 to $4.9 \%$, and from 5.0 to $6.0 \%$ (Figure 1). Furthermore, DGAT1 genotype AA and KK are represented within each group. Genotyping of the DGAT1 K232A polymorphism was performed as part of a previous study (Schennink et al., 2007). In total, 54 cows were selected, 26 with DGAT1 AA genotype and 28 with DGAT1 KK genotype (Figure 1). The 54 selected MF samples belonged to different commercial herds (46 herds in total), and therefore the samples provide the best possible representation of management and feeding regimens.

\section{Analysis of TAG Profile}

Isolation of MF was performed by the Dutch Milk Controlling Institute Qlip Laboratories (Zutphen, the Netherlands) as described by Tzompa-Sosa et al. (2014). Prior to TAG analysis, we performed a qualitative determination of lipid classes to our MF samples by silica gel thin layer chromatography (TLC) according to Tzompa-Sosa et al. (2014). The TLC plates showed that MF had only TAG and no traces of other lipid compounds were found. Therefore, no further purification was performed. 
The MF TAG profile was analyzed by the Dutch Milk Controlling Institute Qlip Laboratories in accordance with the reference method for analysis and quality evaluation of milk and milk products from the European Commission Regulation [Commission Regulation (EC), 2008]. With this method, TAG are separated according to the total number of carbon atoms in the aliphatic chain of the TAG (Christie and Han, 2010). Samples were analyzed in duplicate. The concentration of each TAG was determined as a percentage of total TAG content ( $\mathrm{g} / 100 \mathrm{~g}$ of fatty acids). The absolute amount of each TAG was calculated using the formula

$$
\text { absolute amount of } \mathrm{TAG}_{i}=\frac{\mathrm{FY} \times \mathrm{TAG}_{i}}{100},
$$

where $\mathrm{TAG}_{i}$ is a TAG in $\mathrm{g} / 100 \mathrm{~g}$ of fatty acids (from 24 to $54 \mathrm{Cn}$ ) and FY is fat yield in grams per morning milking.

\section{Statistical Analysis}

The effect of fatty acids, milk production traits (fat content, morning milk yield) and DIM on TAG profile was analyzed using the model

$$
y_{i j}=\mu+\beta x_{i j}+e_{i j} .
$$

The effect of DGAT1 K232A polymorphism on TAG profile was analyzed using the model

$$
y_{i j}=\mu+D G A T 1_{i}+e_{i j}
$$

where $y_{i j}$ are observations for individual carbon number traits (Cn24-Cn54); $\mu$ is the overall mean; $\beta$ is the regression coefficient; $x_{i j}$ is the covariable describing the effect of fatty acids, fat content, morning milk yield, or DIM; DGAT1 is a fixed effect of DGAT1 genotype; and $e_{i j}$ is the residual, which includes differences on feeding and management.

To account for multiple testing, the Bonferroni correction was used to calculate the appropriate significance level. In total, 16 individual carbon number traits (Cn24-Cn54) were analyzed and therefore

$$
\left(P=\frac{\alpha}{n}=\frac{0.05}{16}\right)
$$

$P<0.003$ was considered significant, where $P$ is the significance cut-off; $\alpha$ is the critical $P$-value, and $n$ is the number of comparisons being made. Data analysis were performed using IBM SPSS statistics software (Version 21, Armonk, NY).

\section{RESULTS AND DISCUSSION}

\section{Variability of Milk Fat Triacylglycerols}

Morning milk yield was on average $12.09 \pm 3.2 \mathrm{~kg}$ with a fat content of $4.63 \pm 0.7 \%$ (Table 1), and the cows in this study were on average $175.81 \pm 40.8$ DIM. The fat content in our study was similar to the average fat content reported for winter milk in the Netherlands in 2005 (4.6\% of fat; Heck et al., 2009) and to the reported yearly average fat content for the Netherlands in 2010 (4.4\% of fat; Bijl et al., 2013). The MF TAG profile is shown in Table 1 in relative concentrations (g/100 g of fatty acids) and in absolute amounts (g/ morning milking). The absolute amount is relevant from a physiological perspective because it indicates the amount (in g) of TAG produced in the mammary gland. Triacylglycerols Cn36, Cn38, Cn48, and Cn50 showed the highest values both in relative concentrations and in absolute amounts. Similar values have been reported in other studies where bulk milk was analyzed (Smiddy et al., 2012; Capuano et al., 2013). The coefficient of variation for relative concentrations was highest $(>15 \%)$ for low (Cn26-30) and high molecular weight TAG (Cn52-54) and lowest $(<5 \%)$ for TAG Cn38, which was the most abundant TAG. When TAG profile was expressed in absolute amounts, the coefficient of variation was high $(>20 \%)$ for all TAG, which reflects the large variability in fat yield among cows.

\section{Relation Between Fatty Acids and Milk Fat Triacylglycerol Profile}

The associations of fatty acids (mol \%) in relation to TAG profile measured in relative concentrations (g/100 $\mathrm{g}$ of fatty acids; Table 2) and absolute amounts (g/ morning milking; see Supplemental Table S1; http:// dx.doi.org/10.3168/jds.2015-10592) was quantified. These effects were higher on relative concentrations than in absolute amounts. It appears that fatty acids with common synthesis pathways have similar effects on TAG. We showed that an increase in de novo fatty acids C6:0 to C14:0 increase TAG Cn26 to Cn34, Cn42 to $\mathrm{Cn} 46$ as measured in relative concentrations and absolute amounts. In contrast, an increase in fatty acids C6:0 to C14:0 decreased TAG Cn50 to Cn52 in relative concentrations. Fatty acid C4:0 showed a different effect than the other short-chain fatty acids, probably because this fatty acid is synthesized de novo from elongation of $\mathrm{C} 2: 0$ and can also be obtained from bloodderived fatty acids from rumen fermentation. Moreover, an increase in fatty acids C14:1 cis-9 and C16:1 cis-9 increased TAG Cn44 and Cn46 in relative concentra- 
tion. An increase in long-chain SFA C16:0 and C18:0 decrease low molecular weight TAG and increase high molecular weight TAG, but this effect is only seen when TAG is measured in relative concentrations.

Nonlinear relationships between fatty acids and TAG were also tested by extending model 1 with a quadratic component. For C4:0 and C6:0 we found a significant quadratic relation with $\mathrm{Cn} 38(P<0.001$ and $P=0.003$, respectively). This means that the concentration of fatty acids C4:0 and C6:0 on TAG Cn38 increases until reaching the maximum possible concentration of these fatty acids on TAG Cn38, which is about $12.8 \mathrm{~g} / 100 \mathrm{~g}$ of fatty acids. After reaching the maximum concentration of TAG Cn38, fatty acids C4:0 and C6:0 continued to be esterified at TAG $\mathrm{Cn} 38$, but the concentration of TAG Cn38 will not be increased.

We also studied the association between the saturation index (SFA/UFA) and the ratio $\mathrm{C} 16: 0 / \mathrm{C} 18: 1$ cis-9 with the TAG profile. The saturation index summarizes the effect of all SFA and UFA. The C16:0 and C18:1 cis-9 are the 2 most abundant fatty acids, they are negatively correlated and have an opposite effect on physical properties of MF such as solid fat content. Therefore, the relation between the ratio $\mathrm{C} 16: 0 / \mathrm{C} 18: 1$ cis-9 and the TAG profile was studied. Both the saturation index and $\mathrm{C} 16: 0 / \mathrm{C} 18: 1$ cis-9 ratio showed a significant linear relation with TAG Cn34, Cn36, Cn52, and Cn54 (Figure 2). We showed that the difference on TAG Cn34, Cn36, Cn52, and Cn54 among individual cows can be large (Figure 2). For instance, a difference of $4.8 \%$ in TAG Cn36 was seen between the maximum and the minimum concentration in MF. The relation between $\mathrm{C} 16: 0 / \mathrm{C} 18: 1$ cis-9 ratio and TAG profile found in our study for a dairy cow population are in agreement with other studies investigating the TAG composition in diets rich in unsaturated $\mathrm{C} 18$ fatty acids (DePeters et al., 2001; Capuano et al., 2013). These studies showed that a diet rich in unsaturated C18 fatty acids increase TAG Cn40, Cn50, Cn52 and Cn54 and decrease TAG Cn32, Cn34, and Cn36. Furthermore, an increased $\mathrm{C} 16: 0 / \mathrm{C} 18: 1$ cis-9 ratio implies an increase in $\mathrm{C} 16: 0$ and a decrease in $\mathrm{C} 18: 1$ cis-9, which could increase MF melting point above the cow's temperature. The cow might overcome this problem by increasing the concentration of low molecular weight TAG (Cn34 and Cn36) and decreasing the amount of high molecular weight TAG (Cn52 and Cn54).

The changes in TAG profile seen in this study can have an effect on the mechanisms of MF crystallization. Crystallization starts with nucleation, which is the formation of tiny embryonic crystals called nuclei. Nucleation is related to the concentration of TAG because an appreciable number of TAG (supersaturation) should be present to form a nuclei that can further grow into a

Table 1. Milk productive traits and triacylglycerol (TAG) composition in relative concentration $(\mathrm{g} / 100 \mathrm{~g}$ of fatty acids) and in absolute amount ( $\mathrm{g} /$ morning milking) of milk fat from individual cows on a winter diet (n $=54)^{1}$

\begin{tabular}{|c|c|c|c|c|c|c|}
\hline \multirow{4}{*}{$\begin{array}{l}\text { Item } \\
\text { Fat content (\%) } \\
\text { Morning milk yield }(\mathrm{kg}) \\
\text { DIM }\end{array}$} & \multicolumn{2}{|c|}{ Mean (SD) } & \multirow{4}{*}{$\begin{array}{c}\text { CV (\%) } \\
15 \\
26 \\
23\end{array}$} & \multicolumn{2}{|c|}{ Mean (SD) } & \multirow[t]{4}{*}{ CV $(\%)$} \\
\hline & 4.63 & $(0.71)$ & & & & \\
\hline & 12.09 & $(3.16)$ & & & & \\
\hline & 175.81 & $(40.75)$ & & & & \\
\hline TAG & \multicolumn{3}{|c|}{$\begin{array}{l}\text { Relative concentration } \\
(\mathrm{g} / 100 \mathrm{~g} \text { of fatty acids; } \mathrm{n}=54)\end{array}$} & \multicolumn{3}{|c|}{$\begin{array}{c}\text { Absolute amount } \\
(\mathrm{g} / \text { morning milking; } \mathrm{n}=47)^{2}\end{array}$} \\
\hline Cn24 + cholesterol & 0.25 & $(0.02)$ & 8 & 1.4 & $(0.32)$ & 23 \\
\hline $\mathrm{Cn} 26$ & 0.24 & $(0.05)$ & 21 & 1.3 & $(0.45)$ & 35 \\
\hline $\mathrm{Cn} 28$ & 0.61 & $(0.12)$ & 20 & 3.4 & $(1.13)$ & 33 \\
\hline Cn30 & 1.26 & $(0.21)$ & 17 & 7.0 & $(2.16)$ & 31 \\
\hline Cn32 & 2.8 & $(0.37)$ & 13 & 15.6 & $(4.36)$ & 28 \\
\hline Cn34 & 6.63 & $(0.55)$ & 8 & 36.8 & $(8.88)$ & 24 \\
\hline Cn36 & 11.63 & $(0.8)$ & 7 & 64.2 & (14.49) & 23 \\
\hline Cn38 & 12.2 & $(0.59)$ & 5 & 68.1 & (13.67) & 20 \\
\hline $\mathrm{Cn} 40$ & 9.21 & $(0.48)$ & 5 & 50.6 & (11.79) & 23 \\
\hline $\mathrm{Cn} 42$ & 7.53 & $(0.47)$ & 6 & 41.8 & $(9.54)$ & 23 \\
\hline $\mathrm{Cn} 44$ & 7.63 & $(0.56)$ & 7 & 42.4 & $(9.45)$ & 22 \\
\hline $\mathrm{Cn} 46$ & 8.6 & $(0.56)$ & 7 & 47.7 & (10.15) & 21 \\
\hline $\mathrm{Cn} 48$ & 10.09 & $(0.58)$ & 6 & 55.4 & (11.17) & 20 \\
\hline Cn50 & 10.99 & (1.01) & 9 & 59.7 & $(12.31)$ & 21 \\
\hline Cn52 & 7.56 & $(1.13)$ & 15 & 40.5 & $(9.81)$ & 24 \\
\hline Cn54 & 2.79 & $(0.76)$ & 27 & 14.6 & $(4.56)$ & 31 \\
\hline
\end{tabular}


Table 2. Linear effects of DGAT1 K232A polymorphism, milk productive traits, DIM, and fatty acids on the relative concentrations of triacylglycerols (g/100 g of fatty acids)

\begin{tabular}{|c|c|c|c|c|c|c|c|c|c|c|c|c|c|c|c|c|}
\hline Item & $\mathrm{Cn} 24^{2}$ & Cn26 & Cn28 & Cn30 & Cn32 & Cn34 & Cn36 & Cn38 & $\mathrm{Cn} 40$ & Cn42 & $\mathrm{Cn} 44$ & Cn46 & $\mathrm{Cn} 48$ & Cn50 & Cn52 & Cn54 \\
\hline DGAT1 K232A ${ }^{3}$ & -0.006 & -0.020 & -0.034 & -0.027 & 0.063 & 0.179 & -0.020 & $-0.41^{* *}$ & -0.250 & 0.199 & 0.285 & 0.164 & 0.120 & 0.171 & -0.145 & -0.271 \\
\hline $\begin{array}{l}\text { Morning milk } \\
\text { yield }\end{array}$ & 0.000 & $0.01^{*}$ & $0.013^{*}$ & $0.02^{*}$ & $0.036^{*}$ & 0.025 & -0.043 & -0.009 & $0.05^{*}$ & 0.017 & 0.009 & -0.003 & -0.041 & $-0.10^{*}$ & -0.020 & 0.037 \\
\hline $\begin{array}{l}\text { Fat content } \\
\text { DIM }\end{array}$ & 0.000 & -0.011 & -0.026 & -0.038 & -0.052 & 0.012 & $0.31^{*}$ & 0.209 & -0.035 & 0.046 & 0.017 & -0.030 & -0.052 & 0.034 & -0.151 & -0.230 \\
\hline C4:0 & 0.003 & $0.02^{*}$ & $0.05^{*}$ & 0.058 & 0.074 & 0.187 & $0.51^{* * *}$ & $0.59^{* * *}$ & $0.26^{* *}$ & $-0.27^{* *}$ & $-0.49^{* * *}$ & $-0.52^{* * *}$ & $-0.47^{* * *}$ & -0.271 & 0.045 & 0.223 \\
\hline C6:0 & $0.032^{* * *}$ & $0.14^{* * *}$ & $0.33^{* * *}$ & $0.53^{* * *}$ & $0.79^{* * *}$ & $1.12^{* * *}$ & $1.56^{* * *}$ & $1.65^{* * *}$ & $1.35^{* * *}$ & 0.440 & -0.370 & $-1.13^{* * *}$ & $-1.87^{* * *}$ & $-2.51^{* * *}$ & $-1.76^{* *}$ & -0.264 \\
\hline C8:0 & $0.06^{* * *}$ & $0.22^{* * *}$ & $0.56^{* * *}$ & $1.00^{* * *}$ & $1.58^{* * *}$ & $1.75^{* * *}$ & 0.870 & $0.96^{*}$ & $2.04^{* * *}$ & $1.94^{* * *}$ & $1.02^{*}$ & -0.470 & $-2.41^{* * *}$ & $-4.67 * * *$ & $-3.65^{* * *}$ & -0.796 \\
\hline C10:0 & $0.02 * *$ & $0.07 * * *$ & $0.18^{* * *}$ & $0.34^{* * *}$ & $0.57 * * *$ & $0.61 * * *$ & 0.030 & -0.110 & $0.53^{* * *}$ & $0.93^{* * *}$ & $0.71^{* * *}$ & 0.140 & $-0.60 * * *$ & $-1.52 * * *$ & $-1.40^{* * *}$ & -0.480 \\
\hline C12:0 & 0.005 & $0.04^{* * *}$ & $0.10^{* * *}$ & $0.20 * * *$ & $0.41^{* * *}$ & $0.49 * * *$ & 0.000 & $-0.27^{*}$ & 0.120 & $0.54^{* * *}$ & $0.65^{* * *}$ & $0.45 * * *$ & -0.120 & $-1.02^{* * *}$ & $-1.11^{* * *}$ & $-0.50^{* * *}$ \\
\hline C12:1 cis -9 & 0.100 & $0.49^{* *}$ & $1.19^{* *}$ & $2.33^{* *}$ & $4.66^{* * *}$ & $4.60^{*}$ & -2.006 & -3.261 & 1.535 & $5.36^{* *}$ & $8.60^{* * *}$ & $8.15 * * *$ & 0.307 & $-13.74^{* * *}$ & $-13.46^{* * *}$ & -4.796 \\
\hline C14:0 & 0.000 & & $0.05^{*}$ & $0.11 * * *$ & $0.26^{* * *}$ & $0.35 * * *$ & -0.090 & $-0.35 * * *$ & -0.010 & $0.39 * * *$ & $0.49 * * *$ & $0.35 * * *$ & 0.020 & $-0.52^{* *}$ & $-0.70^{* * *}$ & $-0.37 * * *$ \\
\hline C14:1 cis-9 & 0.010 & 0.050 & 0.120 & 0.210 & 0.370 & 0.290 & -0.450 & -0.400 & 0.080 & 0.330 & $0.82^{* *}$ & $1.04 * * *$ & 0.320 & $-1.33^{*}$ & -1.180 & -0.270 \\
\hline C15:0 & -0.004 & -0.052 & -0.116 & -0.219 & -0.554 & $-1.06^{*}$ & $-1.51^{*}$ & -0.924 & -0.348 & 0.003 & 0.287 & 0.880 & $1.29^{*}$ & 1.021 & 0.809 & 0.498 \\
\hline C16:0 & 0.000 & $-0.01 * * *$ & $-0.02 * * *$ & $-0.03^{* *}$ & $-0.04^{*}$ & 0.030 & $0.20^{* * *}$ & 0.050 & $-0.12 * * *$ & -0.020 & 0.010 & 0.040 & $0.09 * *$ & $0.12^{*}$ & -0.110 & $-0.19^{* * *}$ \\
\hline C16:1 cis-9 & 0.004 & -0.018 & -0.051 & -0.056 & -0.045 & 0.055 & 0.256 & -0.112 & -0.369 & 0.099 & $0.58^{*}$ & $0.96 * * *$ & $0.67^{*}$ & -0.362 & -0.956 & -0.644 \\
\hline C18:0 & -0.004 & $-0.01^{*}$ & $-0.03^{*}$ & $-0.08 * * *$ & $-0.19^{* * *}$ & $-0.35^{* * *}$ & $-0.30^{* *}$ & 0.105 & 0.113 & $-0.21^{* * *}$ & $-0.31^{* * *}$ & $-0.28^{* * *}$ & -0.069 & $0.40^{* * *}$ & $0.76^{* * *}$ & $0.47^{* * *}$ \\
\hline C18:1 cis-9 & -0.002 & -0.005 & -0.014 & -0.037 & $-0.08^{*}$ & $-0.22^{* * *}$ & $-0.41 * * *$ & $-0.15 * *$ & 0.035 & $-0.15 * * *$ & $-0.15^{* *}$ & -0.079 & 0.031 & $0.24^{*}$ & $0.56^{* * *}$ & $0.43^{* * *}$ \\
\hline Total C18:1 trans & 0.004 & $0.05^{*}$ & 0.107 & 0.129 & 0.071 & -0.340 & $-0.95^{*}$ & 0.009 & $0.64^{* *}$ & -0.240 & -0.540 & $-0.61^{*}$ & $-0.60^{*}$ & -0.322 & $1.17^{*}$ & $1.42^{* * *}$ \\
\hline Saturation index & 0.000 & 0.000 & 0.010 & 0.061 & 0.187 & $0.67 * * *$ & $1.40^{* * *}$ & $0.48^{*}$ & -0.216 & $0.39^{*}$ & 0.346 & 0.118 & -0.075 & -0.408 & $-1.57^{* * *}$ & $-1.37^{* * *}$ \\
\hline Ratio 16:0/C18:1 & 0.001 & -0.021 & -0.045 & -0.030 & 0.039 & $0.63 * *$ & $1.78^{* * *}$ & $0.57^{*}$ & $-0.52^{* *}$ & 0.234 & 0.315 & 0.262 & 0.216 & -0.069 & $-1.69^{* * *}$ & $-1.67 * * *$ \\
\hline
\end{tabular}

$\overline{{ }^{1} \text { Effects in bold are considered significant at a level } P<0.003(\mathrm{n}=54) . \text { Bonferroni correction was used to calculate the appropriate significance }(P=\alpha / \mathrm{n}=0.05 / 16=0.003) .}$ ${ }^{2}$ Including cholesterol content. $\mathrm{Cn}=$ carbon number.

${ }^{3}$ DGAT1 KK genotype is set to zero. DGAT = diacylglycerol acyltransferase.

${ }^{* * *}$ Correlation is significant at $P<0.001$ (2-tailed); ${ }^{* *}$ correlation is significant at $P<0.01$ (2-tailed); ${ }^{*}$ correlation is significant at $P<0.05(2$-tailed) 
crystal. This means that nucleation will occur faster in MF with high concentrations of TAG able to nucleate at the given temperature. Further studies on crystallization behavior of $\mathrm{MF}$ are needed to elucidate the concrete effects of differences in MF TAG and fatty acid profile.

\section{Effect of DGAT1 K232A Polymorphism and Productive Traits on MF TAG Profile}

The effect of DGAT1 K232A polymorphism on TAG profile was tested in relative concentration $(\mathrm{g} / 100 \mathrm{~g}$ of fatty acids; Table 2) and absolute amounts (g/morning milking; see Supplemental Table S1; http://dx.doi. org/10.3168/jds.2015-10592). We have shown that DGAT1 K232A polymorphism had a significant effect on the TAG Cn38, which is the most abundant TAG. Cows with DGAT1 KK genotype are increased in this TAG (Figure 3). In the present study, samples were selected in such a way that DGAT1 AA and KK have similar fat content. Therefore, effects of the DGAT1 K232A polymorphism in the current study represent effects adjusted for differences in fat content. A random sample from the population would show larger differences between DGAT1 KK and AA genotypes for fat content and fat composition and corresponding effects on TAG.

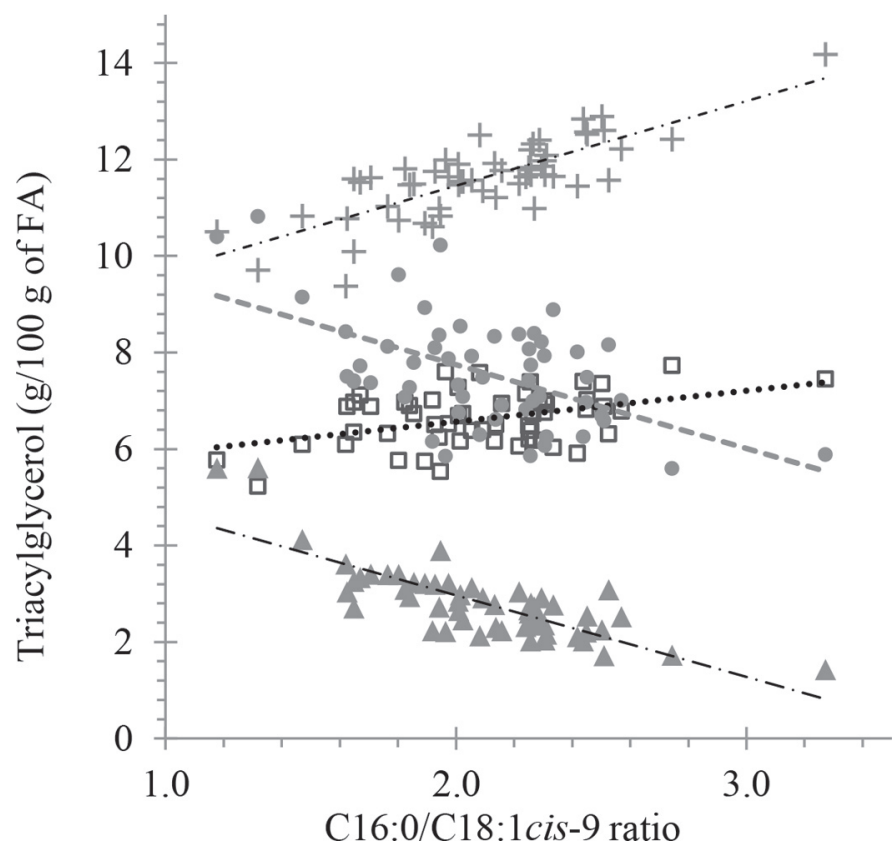

Figure 2. Change of concentration of milk fat triacylglycerols with a change in $\mathrm{C} 16: 0 / \mathrm{C} 18: 1$ cis-9 ratio $(\mathrm{n}=54)$. $\mathrm{Cn} 34(P<0.001)$; $\mathrm{Cn} 36$ $(P<0.001)$; Cn52 $(P<0.001)$; Cn54 $(P<0.001) ; \square \mathrm{Cn} 34 ;+\mathrm{Cn} 36$; - $\mathrm{Cn} 52 ; \boldsymbol{\Delta} \mathrm{Cn} 54 . \mathrm{Cn}=$ carbon number; FA $=$ fatty acid.

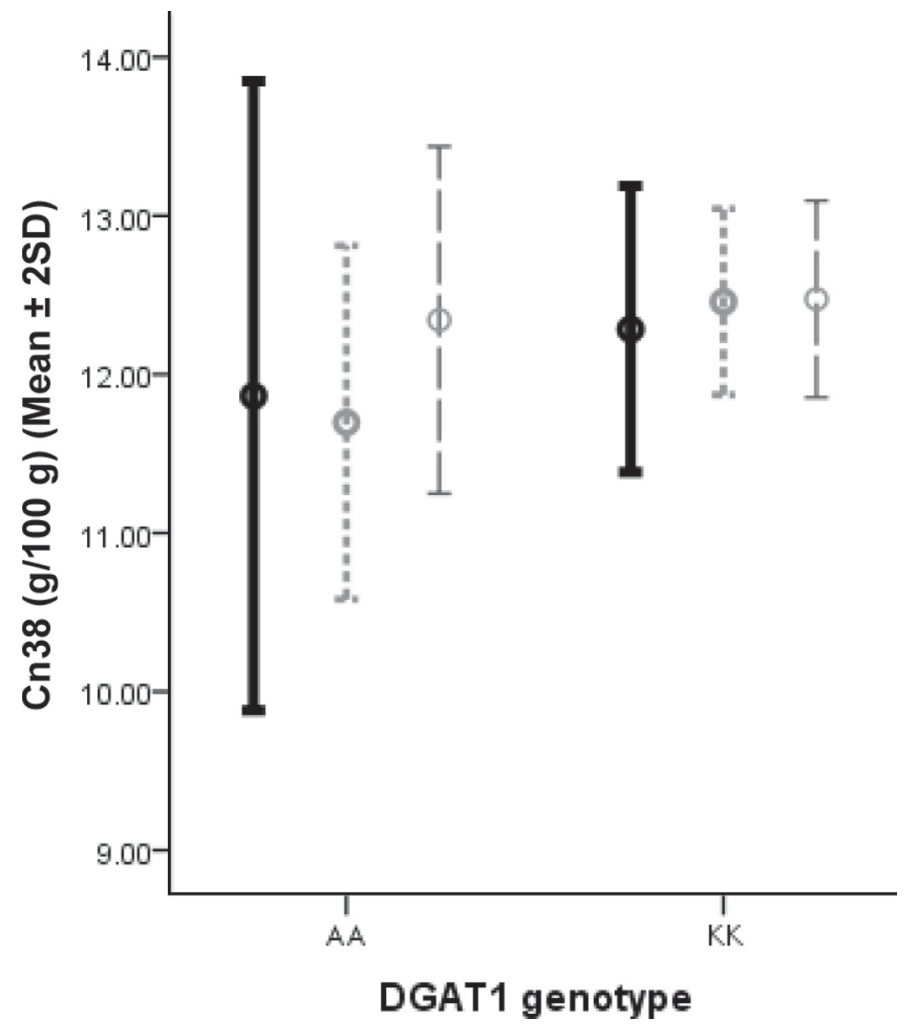

Figure 3. Relative concentration (g/100 g of fat) of triacylglycerols Cn38 grouped per fat content and DGAT1 genotype. DGAT = diacylglycerol acyltransferase. Fat content: 3 to $3.9 \%(-)$; 4 to $4.9 \%$ (----); 5 to $6 \%$ (-- ). Error bars show the range and mean value of $\mathrm{Cn} 38$ per group of fat content. $\mathrm{Cn}=$ carbon number.

The $\mathrm{K}$ allele of DGAT1 is associated with increased levels of TAG Cn38. The average difference of TAG Cn38 in absolute amount between genotypes (AA and $\mathrm{KK}$ ) was $9.49 \mathrm{~g} /$ morning milking, and in relative amounts the average difference was of $0.41 \mathrm{~g} / 100 \mathrm{~g}$ of fatty acids. This difference in TAG Cn38 alone might not be enough to promote a change in the physical properties of MF. However, it shows that cows with the DGAT1 KK genotype produced higher amount of TAG Cn38, suggesting that changes are happening in MF TAG synthesis. The DGAT1 K allele has been associated with an increase in C16:0 fatty acids (Schennink et al., 2007). It is known that TAG species 6:0-16:0-16:0, 4:0-16:0-18:0, and 4:0-16:0-18:0 are the main TAG subspecies in TAG Cn38 (Gresti et al., 1993). We suggest that part of the excess of C16:0 in cows with DGAT1 KK genotype is being esterified in TAG Cn38 together with short-chain fatty acids. In this way, the TAG can decrease its melting point. This mechanism could help the cow to regulate the melting point of MF and overcome the increase in melting point produced by an overall increase in C16:0. A detailed analysis on subspecies of TAG Cn38 can help to further understand 
A.

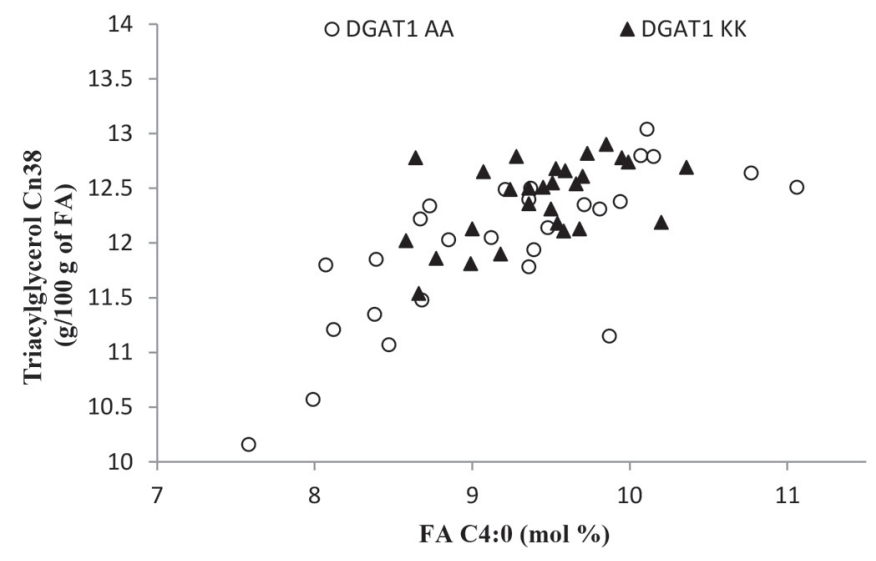

B.

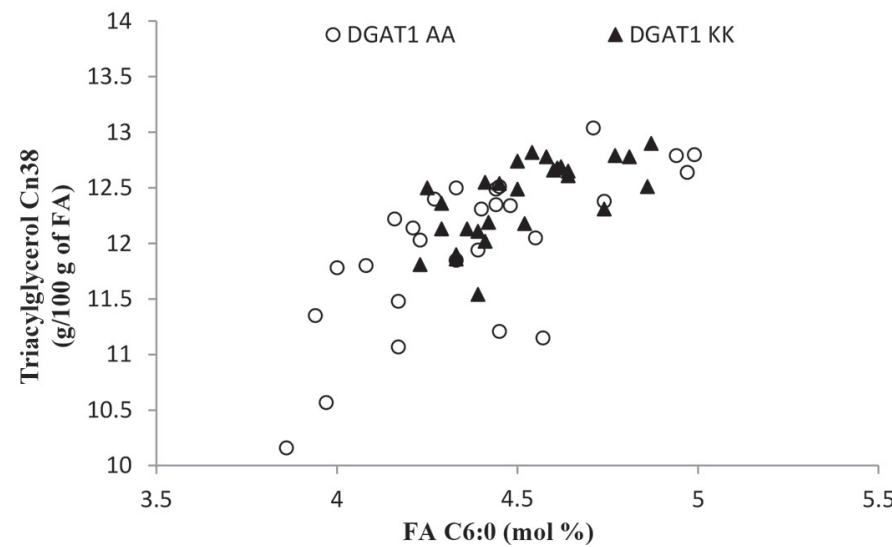

Figure 4. Quadratic effect between milk fat triacylglycerols Cn38 and fatty acids C4:0 (A) and C6:0 (B). DGAT = diacylglycerol acyltransferase. $\mathrm{Cn}=$ carbon number; $\mathrm{FA}=$ fatty acid.

the alterations in MF TAG synthesis caused by the DGAT1 K232A polymorphism.

Previously we discussed the quadratic effect of fatty acids C4:0 and C6:0 on TAG Cn38. We further investigated the interaction between DGAT1 K232A polymorphism and C4:0 and C6:0 on TAG Cn38. We showed that these interactions were significant $(P<$ 0.001; Figure 4). Figure 4 shows the relation between TAG Cn38 and fatty acids C4:0 and C6:0. It is shown that both genotypes of DGAT1 follow the same trend. However, cows with DGAT1 KK genotype are increased in TAG Cn38 and tend to contain a higher concentration of fatty acids $\mathrm{C} 4: 0$ and $\mathrm{C} 6: 0$ as compared with the DGAT1 AA genotype. This confirms our previous suggestion that species of TAG Cn38 from cows with DGAT1 KK are increased in short-chain fatty acids and most likely esterified with fatty acids C16:0.

In the present study, DIM and productive traits, namely fat content and morning milk yield, had no significant effects on TAG profile (Table 2), indicating that these traits do not affect MF TAG synthesis. This is a relevant observation because a considerable increase of milk yield and fat content has been seen in the Netherlands over the last 60 yr (Bijl et al., 2013).

\section{CONCLUSIONS}

The present study provides insight into the variability of MF TAG profile of individual cows. We showed that saturation index (SFA/UFA) and the ratio C16:0/ C18:1 cis-9 significantly affect TAG Cn34, Cn36, Cn52, and Cn54. An increase in the saturation index and in the ratio $\mathrm{C} 16: 0 / \mathrm{C} 18: 1$ cis-9 increased the relative concentration of TAG Cn34 and Cn36 and decreased TAG Cn52 and Cn54. The DGAT1 K232A polymorphism significantly affected TAG Cn38. Cows with the DGAT1 KK genotype were increased in TAG Cn38, measured both in relative concentration and in absolute amounts. We suggest that part of the excess of C16:0 in cows with DGAT1 KK genotype caused by the $\mathrm{K}$ allele is being esterified in TAG Cn38 together with shortchain fatty acids $\mathrm{C} 4: 0$ and $\mathrm{C} 6: 0$. In this way, MF will have a decreased melting point diminishing the effect of a higher C16:0 concentration in MF. The productive traits, including DIM, fat content, and milk yield, had no significant effects with TAG profile. Overall, large differences in MF TAG profile were seen among cows. These differences in MF TAG profile imply differences in its physical properties.

\section{ACKNOWLEDGMENTS}

We thank the Consejo Nacional de Ciencia y Tecnología (CONACYT) from the Mexican government for financial support. We thank the Dutch Milk Genomics Initiative (Wageningen, the Netherlands) for providing the samples for this research. The authors thank Herman van den Brink from QLip laboratories (Zutphen, the Netherlands) for carrying out the TAG analysis.

\section{REFERENCES}

Bijl, E., H. J. van Valenberg, T. Huppertz, and A. C. van Hooijdonk. 2013. Protein, casein, and micellar salts in milk: Current content and historical perspectives. J. Dairy Sci. 96:5455-5464.

Bionaz, M., and J. J. Loor. 2008. Gene networks driving bovine milk fat synthesis during the lactation cycle. BMC Genomics 9:366.

Capuano, E., R. Boerrigter-Eenling, A. Elgersma, and S. M. van Ruth. 2013. Effect of fresh grass feeding, pasture grazing and organic/ biodynamic farming on bovine milk triglyceride profile and implications for authentication. Eur. Food Res. Technol. 238:573-580.

Christie, W. W., and X. Han. 2010. Lipid Analysis: Isolation, Separation, Identification and Lipidomic Analysis. Oily Press Lipid Library; vol. 24. Oily Press, Bridgwater, UK.

Coleman, R. A., and D. P. Lee. 2004. Enzymes of triacylglycerol synthesis and their regulation. Prog. Lipid Res. 43:134-176. 
Commission Regulation (EC). 2008. Commission Regulation (EC) No. 273/2008 of 5 March 2008 laying down detailed rules for the application of Council Regulation (EC) No 1255/1999 as regards methods for the analysis and quality evaluation of milk and milk products. Pages L1-88. Official Journal of the European Union.

DePeters, E. J., J. B. German, S. J. Taylor, S. T. Essex, and H. PerezMonti. 2001. Fatty acid and triglyceride composition of milk fat from lactating Holstein cows in response to supplemental canola oil. J. Dairy Sci. 84:929-936.

Gresti, J., M. Bugaut, C. Maniongui, and J. Bezard. 1993. Composition of molecular-species of triacylglycerols in bovine-milk fat. J. Dairy Sci. 76:1850-1869.

Hawke, J. C., and M. W. Taylor. 1995. Influence of nutritional factors on yield, composition and physical properties of milk fat. Pages 37-88 in Advanced Dairy Chemistry. Vol. 2. Lipids. 2nd ed. Chapman and Hall, UK.

Heck, J. M. L., H. J. F. van Valenberg, H. Bovenhuis, J. Dijkstra, and T. C. M. van Hooijdonk. 2012. Characterization of milk fatty acids based on genetic and herd parameters. J. Dairy Res. 79:39-46.

Heck, J. M. L., H. J. F. van Valenberg, J. Dijkstra, and A. C. M. van Hooijdonk. 2009. Seasonal variation in the Dutch bovine raw milk composition. J. Dairy Sci. 92:4745-4755.
Parodi, P. W. 1979. Relationship between tri-saturated glyceride composition and the softening point of milk-fat. J. Dairy Res. 46:633639

Ruiz-Sala, P., M. T. G. Hierro, I. Martinez-Castro, and G. SantaMaria. 1996. Triglyceride composition of ewe, cow, and goat milk fat. J. Am. Oil Chem. Soc. 73:283-293.

Schennink, A., W. M. Stoop, M. H. P. W. Visker, J. M. L. Heck, H. Bovenhuis, J. J. Van Der Poel, H. J. F. Van Valenberg, and J. A. M. Van Arendonk. 2007. DGAT1 underlies large genetic variation in milk-fat composition of dairy cows. Anim. Genet. 38:467-473.

Smiddy, M. A., T. Huppertz, and S. M. van Ruth. 2012. Triacylglycerol and melting profiles of milk fat from several species. Int. Dairy J. 24:64-69.

Stoop, W. M., J. A. M. van Arendonk, J. M. L. Heck, H. J. F. van Valenberg, and H. Bovenhuis. 2008. Genetic parameters for major milk fatty acids and milk production traits of Dutch HolsteinFriesians. J. Dairy Sci. 91:385-394.

Tzompa-Sosa, D. A., G. A. Van Aken, A. C. M. Van Hooijdonk, and H. J. F. Van Valenberg. 2014. Influence of C16:0 and long-chain saturated fatty acids on normal variation of bovine milk fat triacylglycerol structure. J. Dairy Sci. 97:4542-4551. 